\title{
Foreign language training for older people by using Internet technologies
}

\author{
L. Viktorova, M. Knyazieva, M. Aksyonov
}

\author{
Social Work and Information Technologies in Education \\ National University of Life and Environmental Sciences of Ukraine \\ Corresponding author. E-mail: viktorova17@ukr.net, kmarishka_1997@ukr.net, max9ax9@gmail.com
}

Paper received 15.02.19; Accepted for publication 19.02.19.

\section{https://doi.org/10.31174/SEND-PP2019-188VII77-16}

\begin{abstract}
In the article an adult's informal education problem is reviewed. A necessity in an introduction of a new conception of a foreign language training for older people in described by authors, the creation of a model of the informational educational environment for the older people is proposed and the role of information technologies in adult learning is solved, the need to create a training system for andragogs and gerargists - experts in the education of adults and older people.
\end{abstract}

Keywords: adult education, older people education, third age, model of educational environment, population aging, information technology, case technology, internet technology, brainstorming, distance education, social adaptation, foreign language learning.

Topicality. The problem of studying the learning opportunities of older people is not only scientifically relevant, but also vital, since traditionally old age is perceived as an age of sorrow, loss, anguish and pain suffering. At the same time, social pedagogy, gerontology and gerontopsychology, neurophysiology view old age as the age of development, point to significant differences in the manifestation of individual signs of aging, which do not allow unambiguously establish the age boundary between maturity and old age.

Old age has a special specific role in the human life cycle: it is aging that outlines the overall perspective of personality development, provides a link between time and generations. Only from the standpoint of old age one can deeply understand and explain life as integrity, its essence and meaning, its obligations to the previous and next generations. The transition of a person to an older people group significantly changes his relationship with society and such values and such normative concepts as the purpose and meaning of life, goodness, happiness, etc.

Modern globalization processes necessitate radical changes in the attitude of the Ukrainian society of the older people, which until recently were, to a certain extent, socially isolated, in promoting their development and self-realization.

Implementation of the new strategy of the state educational policy on adult education in Ukraine is aimed at ensuring equal access to quality education. However, the achievement of the priority goals of equal opportunities for the older people require the introduction of a set of measures that will ensure their full adaptation to the learning process, which in the future can ensure the achievement of high personal development indicators and further integration into the social environment, the ability to take a proper place in it.

Older people, or they are also called "People of the Third Age" - one of the most representative socio-demographic segments of our country, and is the most important element of the social structure of Ukrainian society [4, p. 24].

The age boundaries of people of the third age are rather conditional:

- According to the World Health Organization developed by the age classification, people of the third age group will be divided into 3 age groups: older men (60-74), women (55$74)$, old (75-84), and long-term residents (85 years and older) )

- in gerontology - the science of age, aging, life expectancy, life style, which provides longevity, the limits of the third age are defined from 60 to 74 years.

Theoretical analysis of the current state of the problem allows us to formulate some statements that are most often reflected in modern psychological and pedagogical, sociopedagogical literature. First of all, it should be noted the idea of the possibility of rational denial of old age as a mental state, excluding relevant cases of medical nature. Physiological processes, of course, have the property of fatality and irreversibility, but the involvement of a person in intellectual activity can statistically change them to a considerable degree. The creative component of human existence in old age, may be not only a condition for its selfrealization, but also a necessary condition for the translation of its functional activity in time [4, p. 23]. Modern society does not have sufficient organizational and pedagogical means to solve such problems. This requires a scientific rethinking of the problem, as well as the development of special techniques that take into account a wide range of factors, from general to private, including regional and gender.

The general characteristic of people of the third age is a great life experience, which should be used in the organization of work. Work with people of the third age undergoes significant changes and pedagogical functions of a person who assumes the responsibility to carry out such work. When working with people of the third age one of the main features is non-formal learning for the relevant activities [4, p. 31]. The comfort of the educational environment in this case multiplies the resulting effect many times, and the organization of educational programs for the older people, raises the level of their social well-being, playing an important role in preventing the negative effects of the crisis period, increasing their adaptive capacity for internal and external changes.

Analysis of recent researches and publications. The analysis of scientific literature shows that many domestic and foreign researchers have studied the problems of teaching older people, as well as the problems of their socialization. For example, the study of the involvement of the older people in education and their successful socialization are dedicated to the research of G.M. Andreeva, L.S. Vygotsky, AN Leontiev and others. Educational Gerontology as a direction of scientific and pedagogical research has developed in the writings of foreign scientists, and the conceptual foundations of education of the older people/ third age have been substantiated in the works of S. Bass, R. 
Weiss, F. Williamson, F. Glendenning, C. James, A. Zych , A. Lemieu, H. Russel, W. Sadler.

At the same time, the global process of transition from the industrial to the new stage of human development - the information society - requires significant changes in many spheres of activity. First of all, this concerns the reform of education, modernization of which as a condition for Ukraine's transition to an innovative way of development involves a whole series of steps aimed at changing the content of the training structure of specialists. Today, the new conditions of professional activity require revision of both the general methodology and the specific methods and methods of teaching foreign languages, in particular older people.

Interesting researches and publications on the implementation of information technologies for adult learning are works of: O. Andreeva, V. Yu. Bykova, O. I. Gorokhovsky, R. S. Gurevich, V. V. Ilyina, G. A. Kozlakova , A.P. Kudin, V.M. Kukharenko, N.V. Morse, V.V.Oliynyk, J. Bartram, T. Bates, M. Beaudoin, B. Lockee, S. Catherine, F. Willits, M. Cornelia, S. Feldman, G. Randy, N. Hara, R. Jones, B. Lockee, A. Mishra, T. Nunan, F. Saba, M. Soby, C. Wedemeyer, R. Widdison et al.

The purpose of the study $\neg$ to outline the principles of creating a model for the informational educational environment for the older people and to reveal the role of information technology in teaching foreign language and to describe the methodical principles of foreign language training of older people by means of Internet technologies.

Research methods. To solve this problem a set of methods was applied: scientific and theoretical analysis and synthesis of foreign and domestic pedagogical, philosophical, psychological literature, comparativehistorical method, structural method, generalization.

Results of the research and their discussion. The informatization of the sphere of education becomes more and more important today and enters a new stage in its development. The learning process introduces new information, multimedia and other computer technologies. Accordingly, issues of relevance to a broader understanding of the capabilities of the computer, including its place, role and functions in teaching foreign languages, are relevant. That is why the important direction of improving the level of teaching a foreign language is the use of various techniques, in particular those based on modern information technologies, which carry out informative, shaping, motivating, systematizing and controlling functions in the educational process.

Information technology (IT) - a set of methods, production processes and software and hardware integrated with the purpose of collecting, processing, storing, distributing, displaying and using information in the interests of its users [7, p. 256].

Technologies that provide and support information processes, that is, processes for the search, collection, transmission, storage, accumulation, replication of information and procedures for access to it.

Information and communication technology (ICT) - from the English information and communication technology (ICT) - is often used as a synonym for information technology (IT), although ICT is a wider term that emphasizes the role of unified technologies and the integration of telecommunications (telephone lines and wireless unions), computers, software, software, storage and audiovisual systems that allow users to create, access, store, transmit, and modify information [7, p. 257]. In other words, ICT consists of IT, as well as telecommunications, media broadcasts, all types of audio and video processing, transmission, network management and monitoring functions.

Combining information and communication technologies, designing them for educational practice, it should be noted that the main task before their introduction is adaptation of a person to life in the information society.

First, the introduction of ICT in modern education significantly accelerates the transfer of knowledge and accumulated technological and social experience of mankind, not only from generation to generation, but also from one person to another.

Secondly, modern ICTs, improving the quality of education and training, enable a person to adapt more successfully and faster to the environment, to social change. This gives each person the opportunity to get the necessary knowledge today and in the post-industrial society.

Thirdly, the active and effective implementation of these technologies in education is an important factor in the creation of a new education system that meets the requirements of the IP and the process of modernizing the traditional education system in the light of the requirements of the post-industrial society.

The importance and necessity of ICT implementation in education is grounded by international experts and scholars. ICT affects all spheres of human activity, but, apparently, they have the strongest positive impact on education, since they open the door to introducing completely new methods of teaching and learning.

Since obsolete methods and teaching methods do not meet the current requirements and are not subject to trends in the rapid development of scientific and technological progress, this encourages the implementation of innovative teaching methods and the use and adaptation of these technologies in the educational process. Particularly this problem is acutely encountered in the formation of professional skills and skills of the older people, since for the effective organization of their training, it is necessary to use a large number of visual materials and interactive means, which in turn contribute positively to the improvement of the achievement of the educational goal.

Didactic capabilities of electronic learning tools for foreign languages are designed to promote: better learning; the formation and development of different types of skills and abilities, namely, listening skills based on adapted and authentic audio texts, abilities of monologue and dialogical speech, skills and abilities of translation and referencing of texts on the specialty, skills and abilities of reading with direct use of materials of the Internet and local networks; increase of informative capacity and visibility; expanding active and passive dictionaries; acquaintance with the vocabulary of modern foreign language, which reproduces the culture of a certain country, its political and social structure of society; the formation of creativity, the development of creative activity of the learner; the formation of the motivation of cognitive activity, the need for using a foreign language in interactive communication; enhancement of the motivation of independent work; the possibilities of individualization and differentiation of work, choosing the pace and 
volume of educational material, the level of its complexity; to expand the possibilities of control with feedback and diagnostics, to increase its objectivity; creating a positive psychological atmosphere during independent work.

Computer programs and their functions can be classified as training, auxiliary, instructional, reference, controlling, educational-game [6, p. 8].

An essential feature of all types of computer training programs is their interactivity, the availability of feedback, which can be both external and internal. External feedback allows the teacher to monitor, evaluate and correct the interaction between the student and the computer. Internal feedback allows the student to make certain conclusions about the effectiveness of their own learning activities, provides the necessary assistance and clarification, and also, if necessary, demonstrates the correct answer or way of performing certain actions [6, p. 45].

A significant number of electronic learning tools are multifunctional. These are electronic textbooks and tutorials that contain systematic teaching material in accordance with the requirements of the teaching program, including a foreign language. The development of electronic textbooks is one of the leading directions of activity of institutions of higher and postgraduate education, working on introduction of distance learning.

It should be emphasized that distance learning was one of the forms of learning using the latest information and communication technologies.

There are many definitions of this concept, so try, summarizing the experience of scholars, to clarify their definition of such a concept.

Distant education (education at a distance) in the world arose as a result of the adaptation of the educational sphere to changing socio-economic conditions and was associated with the need for rapid training of personnel demanded by new industrial relations and situations.

So, according to O. Samoilenko, distance education is a universal form of learning based on the use of a wide range of traditional and new information and telecommunication technologies, as well as on technical means that create conditions for the free choice of educational disciplines and dialogue with a teacher for a student or listener ; while the learning process does not depend on the location of its participants in space and time [8, p. 31].

We share the opinion of V. Kukharenko that distance education is a kind of educational system in which the use of distance learning technologies is predominantly used. Also, TO - one of the forms of education, according to which the mastery of one or another of its level of knowledge in one or another specialty is carried out in the process of distance learning (DN) [8, p. 32].

The implementation of distance learning requires the use of special pedagogical technologies for distance learning:

1) case technology - pedagogical technology, based on the compilation of a typical or individual case containing a package with educational literature, multimedia video course, virtual laboratory and training programs, manuals, fragments of monographs with comments of the teacher, control tasks in the form of tests, etc .;

2) television technology involves the use of multilateral video-teleconferencing, one-way video broadcasts;

3) Internet technology involves the use of video conferencing, Internet radio, Internet -TV, voice mail, E- mail, chat rooms, forums [5, p. 49].

Such technologies are based on competent and personality-oriented approaches and use modern teaching methods: project method, situational learning, collaborative learning, problem-based learning, productive learning, brainstorming, pair and collective learning [5, p. 50].

In the process of studying foreign languages, it is expedient to use such technologies in various types of studies in information retrieval, experimental research and independent educational activities, in particular, in the activities for the purpose of processing received information, gaining knowledge and forming skills and communication skills.

The effectiveness of working with people with the older people depends on the creation of a special learning environment, team approach, psychological and collectable support, rationally selected training strategies. An important role belongs to a teacher who organizes and provides optimal learning conditions, a supportive atmosphere in such a group, a way of presenting a topic that would engage in activities, was fascinating and not burdensome or exhausting for a "special" person, stimulated the absorption of information, promoted the use of knowledge, the ability to relate them to life, to assess achievements in a different way.

Recently, the number of programs and projects implemented in the field of information education has increased. The use of computer technology for teaching foreign languages has greatly changed the approaches to the development of teaching materials in this discipline.

Introducing into the learning process of new information technologies contributes to the successful solving of such pedagogical tasks as:

- realization of the principle of individualization of the educational process;

- increase the efficiency of students' cognitive activity;

- wide introduction of the principle of interactivity.

Unlike traditional, interactive learning based on multimedia applications, it allows you to perfectly implement a whole range of methodological, didactic, pedagogical and psychological principles, making the learning process more engaging and creative. Thus, the ability to take into account the level of language training of those studying and to develop tasks of varying degrees of complexity within the framework of one program serve as a good basis for implementing the principle of individualization and a differentiated approach in teaching a foreign language. This ensures compliance with the principle of complex difficulty and availability of tasks, taking into account the individual pace of work of each person.

The use of new information technologies in teaching a foreign language involves the active position of the learner in the process of learning knowledge. A new kind of cognitive activity excludes passive perception of information. This activity is carried out during intense mental activity, which requires concentration and maximum attention, resulting in new knowledge.

To do this you need to use, first of all, problem technology. In particular, it positively influences the quality of assimilation of the new material. The reception of an advanced task at the beginning of the lesson: the teacher announces the subject and warns the pupils that they will draw conclusions and explanations independently at the end of the class or subject. When preparing them for active 
perception of new foreign language material, the teacher is expanding the work on the disclosure of the content of the title of the topic or lesson.

Problematic situations are also appropriate when introducing older people into the atmosphere of foreign communication. They make it possible to switch their attention from the form of expression to its content and thus remove the initial communicative barrier. The presentation of educational problems must be carried out in different ways, namely: by colliding with life events, facts that require substantiation, the search for new means of foreign language communication; through the use of educational and life situations of real communication, which require analysis of the behavior of the native speaker, cultural phenomena; by setting up research tasks; by inducing the analysis of facts and phenomena of reality, to their comparison, comparison, opposition, collision with the perceptions of life and scientific concepts about these facts, for example, during the analysis of linguistic studies material; by promoting hypotheses and organizing their research, for example, during a role or business game on authentic material or in the process of working on a research project in a foreign language; through familiarization with facts that, at first glance, have no explanation [1, p. 109].

In the process of studying foreign languages with the older peopleit is necessary to use specially designed language situations that involve an open, insufficient solution to the main problem that prompts them to seek other possible solutions, the development of the situation at a new level and, as a consequence, new searches for expressing their thoughts. foreign language.

The most powerful language in terms of such a linguistic educational situation, which is involved in the role of the participant, the teacher himself. That is, the problem that arose, he considered not as an educational, but as a real, which he had to solve on a par with those who study [1, c. 26].

During the online course of foreign language teaching, a variety of linguistic educational situations are widely used linguistic (How it will be in a foreign language? False friends of an interpreter, Metaphors in terms of idiomatic language, Proverbs in texts), professionally oriented (Received instruction in a foreign language. Got new materials. Meeting on the company's work planning, Emergency situation), sociocultural (Organization of the visit of foreign guests, Corporate Strategy, Corporate Social Responsibility, Global Company and its Functioning ents in socio-cultural context), methodological (How to find information. How to check your translation. How to write a resume).

Today, foreign language teachers are actively using modern technologies of brainstorming and rolstroming [2, $\mathrm{p}$. 8].

Brainstorming is an operational method of solving the problem by stimulating the creative activity of those who are learning, inducing them to spell or spell as many options as possible to solve the problem. In essence, brainstorming is an expert assessment method. In the technology format, to the main stages of the brainstorming deployment (problem statement, idea generation, grouping and evaluation), a phase of synchronization of the participants' actions according to their recognized pattern (image) of the process process (process pattern recognition) and the final adoption of a single joint decision [2, with. 9].
The technology toolbar for the battlefield is problematic issues, illustrations and presentations with indeterminate data, video clips, comics, demonstrations. During the generation and selection of ideas, the following modularlocal pedagogical technologies of teaching foreign languages are used: interactive - "2-4 all together", "PRES method", "borrowing position", "openwork"; development of critical thinking - " Believe-or-not", Vannevar bush, intelligence cards, T-schemes, etc. [3, p. 9].

A kind of battlefield is rolestorming, a technology that differs only in the fact that during a brainstorming person or group of individuals generates ideas in accordance with a predetermined roles position. This approach is used when the uncertainty of those who are learning to express their own point of view on a particular problem is expected. By giving them the opportunity to hide behind the avatar (a connoisseur, expert on a particular issue of this problem, ordinary citizen, consumer, buyer, manager, psychologist, sociologist, etc.), the teacher receives greater effectiveness from generating a variety of ideas by pupils [3, p. 10].

Certain pedagogical technologies of teaching foreign languages can be used at each stage of learning foreign language knowledge, and the positive effect in the preparation of the older people, as the research showed, provided training technologies.

The conceptual idea of training technology in general is to create the proper conditions for the transition of one or the given information into the personal experience of the training participant. According to the goals of studying foreign languages by older people, the most effective ones are two such types of training: as a method of training and training as an active learning form. The main purpose of these trainings is to formulate certain foreign language skills.

The technology of organizing and conducting the training is implemented in the following way: problem statement $\rightarrow$ awareness of those who learn, the need to learn foreign language knowledge $\rightarrow$ organization of the system of exercises to gain experience in solving certain educational problems (on verbalization, automation and autonomy) $\rightarrow$ reflection of the experience [3, with. 38].

In the process of properly organized training technology, the older people reaches a rather high level of selfawareness, reflexivity, self-discipline, personal responsibility. For this purpose, you can use a variety of training sessions - Pronunciation training, Pronunciation training, Speech training, Speech training, Reading training, Writing training, Foreign language training (Contact making training).

The elements of self-education training, as well as training on working on discussion issues, are also desirable [3, p. 39].

In its turn, the creative nature of educational and cognitive activity contributes to the development of cognitive autonomy of the older people, the formation of skills for selfreplenishment of knowledge, search and orientation in the flow of information.

It should also be noted that the visualization of educational material - the creation of a learning environment with a clear presentation of information, using color and sound, affecting the emotional and conceptual spheres, contribute to a more profound assimilation of linguistic material.

Information and communication technologies at the same 
time stimulate people with special educational needs several channels of perception, better support his attention, contribute to reducing fatigue and provide the necessary relaxation. In turn, the combination of visual perception of the text and sound series provides great opportunities for the complex development of speech skills in a foreign language. This process is interactive, thanks to the possibility of twoway communication, a dialogue with the computer, when the learner and the computer can ask each other questions, receive answers when the computer can give corrective tips and you can ask for help.

The great advantage of automated training systems is their ability to record, store and analyze responses, provide them, if necessary, help, provide a gradual and continuous evaluation of knowledge, and determine the success of their work, that is, to implement a more flexible control system for assimilation and assessment of knowledge. Along with this, the availability of various keys to the programs also provides an opportunity to carry out self-monitoring. Creating quality training and controlling programs is a complex process that requires a lot of time and effort from foreign language teachers, linguists and methodologists, as well as specialists in the field of computer technology. The result of such creative work is multimedia programs that can be used both in the traditional method of teaching a foreign language and in distance learning

In addition, the introduction of computer networks in most educational institutions and private homes in recent years has provided more and more people with the opportunity to develop their language skills using techniques that were not possible until recently. One of the innovations in teaching a foreign language is the use of a virtual classroom, or so-called object-oriented environment, designed for many users.

Thus, in the process of foreign language training of the older people, it is necessary to use interactive technologies of teaching foreign languages - cooperative training, collectivegroup training, situational training, discussion of discussion issues, etc. In addition, such technologies make it possible to focus the learner, not only on speech, but on the problem, to shift the emphasis from the linguistic aspect to the content.

Conclusions and perspectives. The relevance of the adults' worlds is an acknowledged fact. The overwhelming majority of countries are obliged by their economic progress exactly to this very educational direction.

Due to the increasing life-time of a person and the number of older people, in science and in social practice, the interest in gerontological problems has increased significantly.

The specifics of the education of the older peopleconsists in the fact that its contingent is people who combine educational activities with personal life experiences. Therefore, this kind of education can not translate traditional postulates of pedagogical theory, forms and methods of teaching and upbringing of the younger generation. Consequently, there is an urgent need to establish a system of training andragogs and gerrhogs - experts in the education of adults and the older people. Without modern knowledge of the older peopleand the mastery of modern methods and technologies, it is impossible to achieve the efficiency and quality of the educational process, which will provide optimal conditions for successful aging.

The foreign language training of the older people, in the current realities of Ukraine, is most effective in the process of distance learning by forming a positive motivation to study (providing the opportunity to choose an individual trajectory of learning in accordance with their own pace of educational and cognitive activity, use of training, active methods of control (web quests , cases, projects), rating assessment based on individual, group, expert and mutual evaluation); immersion in a polyling environment for the improvement of their communicative skills and abilities (active introduction of technologies of individual, pair, collective training), which enhances the traditional course of materials reference information, teaching methodological, control and diagnostic purposes).

The content of the article does not exhaust the essence of the problem and needs further search for ways to intensify the process of learning foreign languages of different categories of adults.

\section{REFERENCES}

1. Vereschagyn, E. M., Kostomarov V.G. (1983). Yazyk i kultura: lyngvostranovedenye $v$ prepodavanii russkogo yazyka kak inostrannogo. Moskow : Russian language.

2. Vetoxov, A. M. (2000). Uslovye uspeshnogo obucheniya inostrannomu yazyku. Foreign languages, 4, 8-10.

3. Vyetoxov O. (2004). Samostiyna robota uchniv z ovolodinnya inozemnoyu movoyu: psyxologichni umovy efektyvnosti. Native school, 2, 36-39.

4. Viktorova L., Kocharian A., Korotun O. Technologies in foreign language education for the "thirdage" learners // Information Technologies and Learning Tools. 2018. Vol 63. №1. - P.22-35. - URL: https://journal.iitta.gov.ua/index.php/ittl/article/view/1940

5. Pexota, O. M.,. Kiktenko, A. Z, Lyubars`ka, O. M. (2001). Osvitni texnologyi : navchalno metodichyi posibnyk. Kyiv : A.S.K.

6. Ministry of Education and Science of Ukraine (2012). Reforma systemy osvity $v$ rik osvity ta informaciynogo suspilstva. Retrieved from http://mon.gov.ua/index.php/ua/diyalnist/reforma-osviti.

7. Sysoyeva, S. O., Aleksyuk, A. M., Volovyk, P. V., Kulchyczka O. G. (2001). Pedagogichni texnologiyi u neperervniy profesiyniy osviti : monografiya. Kyiv : VIPOL.

8. Yutkyna Yu. Dystancyonnoe obrazovan e: plyusy i mynusy. Retrieved from http://www.fm1raimng.rumodules.php?op=modload\&name=Ne ws $\&$ file $=$ article $\&$ sid $=304$ 